\title{
Integration of School Management Systems Using a Centralized Database (ISMSCD)
}

\author{
Romeo E. Balcita and Thelma D. Palaoag
}

\begin{abstract}
School have different departments and offices with interrelated functionalities that needs one's cooperation in order to function well. Offices are scattered across the campus and transfer of information is affected. The need to build an integrated School Management System using a centralized database will make school services of better quality. The need to integrate technologies like barcodes, use of internet, video cameras, sensors and the use of a better framework are needed to cope up with the changing needs of the society and in providing quality school service. Thus this study aimed to build such system, implement the system and identify the level of acceptability. Features of the system include enrollment, assessment, report generation and providing decision support module. The system is based from a standardized school management framework derived from different existing school management systems. This is under qualitative as well as descriptive research. Agile AWE model is used in the project development. This is implemented in an institution that uses manual process of school management. Manager, staff, teachers, students and guardian will provide the needed system requirements and at the same time they will be the respondents in getting the level of acceptability. Feedbacks are continuously gathered and helps identify possible improvements. This system is beneficial to institutions currently using manual process in their departments. This is a fully functional and configurable system that will suit to the needs and surely provide quality service.
\end{abstract}

Index Terms-School management system, centralized database.

\section{INTRODUCTION}

School Management System (SMS) is an information and data processing system that consist of integrated sub-systems for managers, teachers, staff, guardians and students. SMS aims to help school management to improve all the services provided by the school. The adaptation of technologies as well as improving features of SMS will continue to carry on, as the needs of people concern in the services of the institution continuously changing. Faster and convenient service using different platforms is of primary concern [1]. Schools using standalone applications in different offices are not sufficient anymore to provide quality services. It limits the capability of users providing output slowly and of low standards [2].

Other schools are still using manual process. The growing number of clients affects already the services provided by

Manuscript received January 13, 2020; revised April 7, 2020.

R. E. Balcita is with the Northern Philippines College for Maritime, Science and Technology, Brgy. Lingsat, San Fernando City, La Union, Philippines (e-mail: romeo_balcita@yahoo.com).

T. D. Palaoag is with the University of the Cordilleras, College of Information Technology, Baguio City, Philippines (e-mail: tpalaoag@gmail.com) workers. Client's records needs to be checked and updated from time to time now but they are doing this by manual searching and writing. Transactions are very slow, records errors are greater, miscommunications can happen anytime, error in computations, mishandling of data, slow production of reports and performance of employees are not that satisfying. This will result to student's perception that the school is of low quality in all aspect of its services [3].

School managers are the head of the institution. They need to analyze lots of data in order to come up with decision making. Major success of the school lies on them. Providing them tools that helps them in their decision making is very essential nowadays. They need decision support systems to provide a quality service that satisfies clients. Some are no yet familiar how powerful information technology is. They use computers but not as efficient as the computer can provide [4]. They use standalone applications that provide similar result of that of manual process. Other school managers that tried using SMS verify that their productivity and performance improves beyond their expectations. A complete SMS provide all their needed information necessary in their decision making process.

Computerized information systems have been developed and applied in schools throughout the world, and shows significant improvement especially in the decision-making process. But an incomplete SMS will not provide the most efficient service. Incomplete SMS lacks other modules. It contains the key components but other offices are not integrated due to prioritizing components. An incomplete SMS have problems like less integration of office services [5]. Some reports are still manually prepared. Human errors are greater and still time consuming for other manual processes.

Thus, the aim of this study is to integrate SMS using a centralized database. The need to use a carefully analyzed framework must be considered to improve the performance of SMS. This study will also identify SMS features, build the SMS, identify technology needed and incorporate it, implement and verify the level of acceptability of the system.

\section{CONCEPTUAl Framework}

Building a School Management System (SMS) needs strong foundation like finding the right components and analyzing existing frameworks for improvement [6].

The need to adapt to the latest trends in Information Technology (IT) will help improve the quality of education and handling various activities of the school. The use of technology changed the quality of education for the better [7]. It makes procedures and systems, better integrate with factions, departments and various stakeholders. Productivity and performance are enhanced, maximizing employee's 
potentials or even recognize them Using information systems increases managerial effectiveness by directing strategies [8]. But all this is possible only by using an efficient system. A system builds with a modeled framework which delivers the key functionalities making work much easier for administrators, faculty, students and other stakeholders [9].

Schools have different offices with their own policies and procedures [10]. Components needed for building SMS must be identified together with its functionalities and procedure. Literature review of existing system is conducted to identify these components. Common components and added components must be identified for the scope and delimitation of the study. Also, the framework of the system must be built based on the user requirements and components of existing systems. For this study, an SMS framework must be presented, showing the key components and system modules of the system.

Proving the system's effectiveness is an essential part. It shows the quality of the system and gives assurance to users [11]. Feedbacks and tools to measure effectiveness must be presented. Fig. 1 shows the factors affecting system's effectiveness

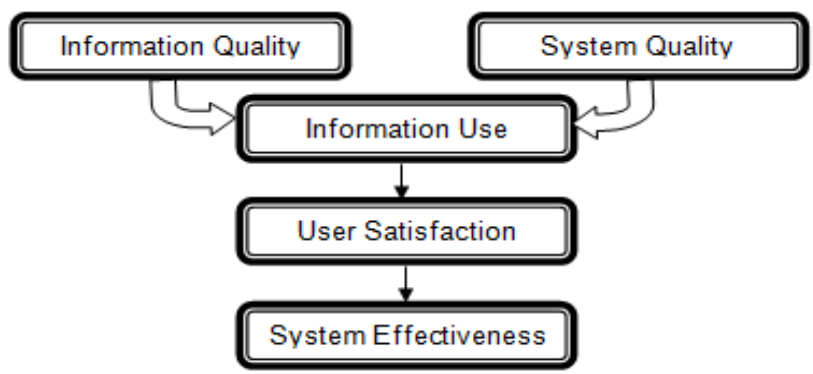

Fig. 1. Factors affecting system effectiveness.

Information use is determined by two factors, information and systems quality which lead to user satisfaction. Feedbacks from users will determine the systems effectives. A tools must be used to measure the system effectives like the Technology Acceptance Model (TAM), see Fig. 2.

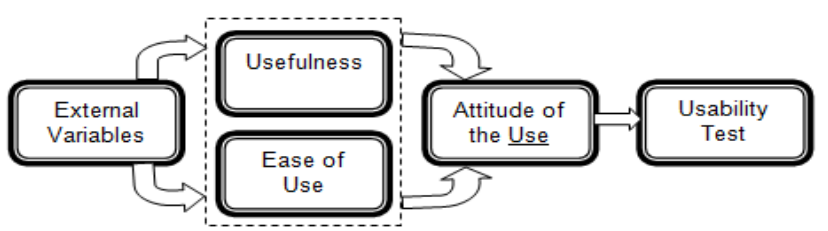

Fig. 2. Technology acceptance model.

This study uses the System Usability Scale (SUS) to identify the level of acceptability. It has ten (10) questions that are based from the factors affecting systems acceptance. This is best for surveys with small sample size. Fig. 3 shows the score guide of the result in using SUS.

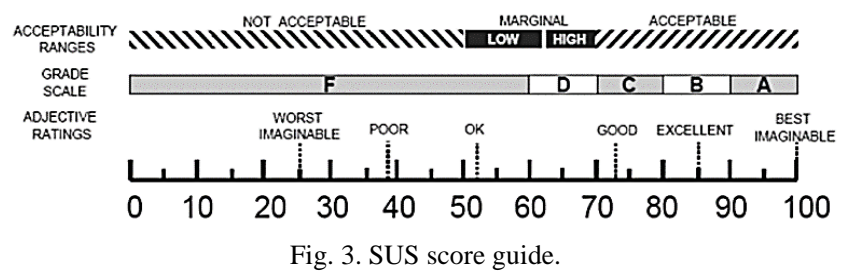

For this study, the Agile Web Engineering (AWE) model is used. Fig. 4 shows the Agile AWE model used in the system development of the SMS.

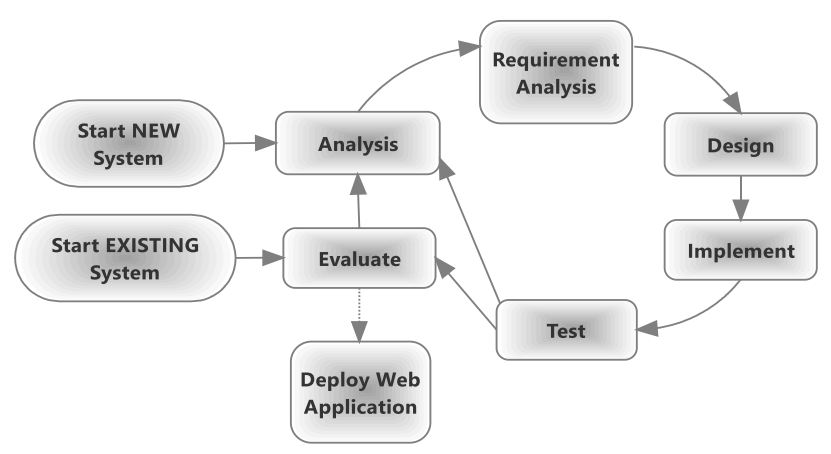

Fig. 4. AWE development cycle.

AWE model is good for system development in a web platform and supports fast pace development of multi-systems [12]. System of the different offices is created one by one until all the components of SMS are done.

\section{DISCUSSION OF FINDINGS}

\section{A. Components of SMS}

School management is directly related to business management methods [13]. Business management has three primary organizational management processes, the resource management, processes management and outcomes management [14]. This has leads to the pyramid model of school management consisting of three components, resource management, processes management and outcomes management [15].

For the resource management, this element deals with the handling of inventory as well as purchases. The proper handling of resources and budget management contributes to the improvement of the school [16].

Processes Management involves task like evaluation, syllabus development, administrative processes, schedule planning, organizing, arranging, eliminating, and updating processes of school. Policies and procedures, collaborations and integration of different offices involved [17].

Outcomes management concerns with the processing of output, discovering standards, generation of reports as well as suggested revisions for improvements [18].

This pyramid model of school management provides insights about the components, modules, functions and features of the SMS. But using this model requires good management.

Good management results to quality service. Nowadays effective management requires the help of technology [19]. Technologies like barcoded identification (ID), use of internet, video cameras, sensors and computer systems [20]. Barcoded ID's is still one of the cheapest ways to handle different services. Barcode gives unique identification that can be applied for instant searching of records. It can be used student entrances, assessment, library transactions, and academic concerns. The use of internet for school services provides another improvement. School websites can provide availability of information to all people concerned. With student's online account, one can view his own records like grades, schedules, and assessment concerns. Teachers can 
enter grades anytime anywhere and view needed information with the availability of the internet. Student's guardian online account, giving them information to student's attendance and grade monitoring which will give them ease of mind.

Finding the needed components for SMS is very essential. SMS wide scope makes it complicated to identify the needed components. Existing SMS like Engage, ELCEN, FeKara, MySchool, AscendSMS, and SchoolTool were studied and analyzed which results to identifying the four key components of SMS: admission, fees, assessment and academics module

Admissions. Student fees associated with their details and parent details will be processed here along with fee receipts. Modules associated with these includes: admission inquiry, admission form, confirmation of fees, online accounts associated with the school websites.

Fees Management. This includes various transactions concerning payments of students. Providing updated mapping with account and generating comprehensive fee reports.

Student Assessment. This includes ways to assess students as well as recording outputs. It also provides ways for easy communication between student and teacher.

Academic. This includes functions like updating daily classwork, assigning homework, organize lesson plan, syllabus scheduling and updating completed lesson.

Other components of SMS include admission management, fees, academic management, inventory, hotel management, guardian, teacher, employees management, student transport, report generation, online module and library management.

\section{B. Architectural Framework}

This study uses 3- tier architecture. MySQL server runs as backend data tier, business rules represented in PHP as the middle logic tier and web server as the third presentation tier.

Tier-1. MySQL server is chosen as the system's backend repository for its strengths in referential integrity, triggers, and supports of multiple users' access. Connectivity between MySQL server to the application is an easy task to PHP.

Tier-2. Business logics govern the policies involved in school management. Modules are created using PHP codes. The PHP files reside on the platform as the web server connector on the presentation tier. The business logics are stored in PHP due its portability and platform independence. A PHP file is portable to multiple operating systems though it was created in a single operating system.

Tier-3. Presentation is based on HTML. This is used develop the interface and interaction between users and the system.

Fig. 5 shows the SMS components integration framework. It consists of components like the administrator, registrar, guardian portal, student portal, library, accounting, academic affairs, student affairs office, student body organization, security office, clinic, human resource office, maintenance and dean's account.

Registrar. This module handles managing departments, degrees, curriculum and subjects. Student records as well as guardians are managed here including the processing of accounts. Since registrar handles enrollment data, subject offerings, class card, enrollment list, and Student Affairs Office (SAO) report are managed here.

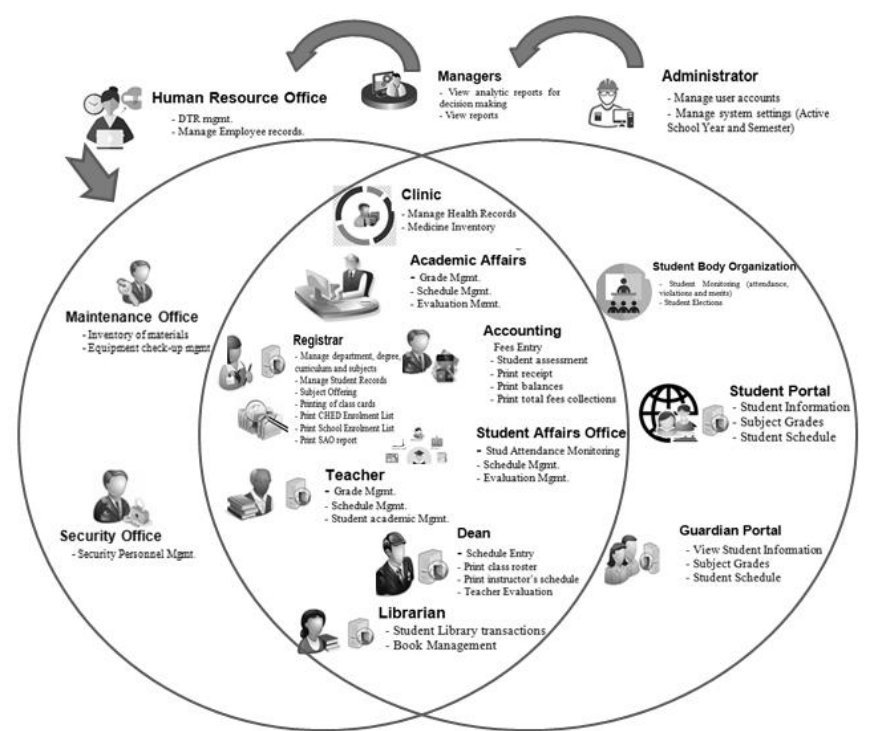

Fig. 5. SMS components integration framework.

Administrator. This module handles accounts of employees. System settings are managed here regarding school year and semester.

Manager. Different analytical reports were presented in this module for decision making. It includes reports like financial reports, student academic relating to other factor report, examination questionnaire difficulty status, quality assurance report and guardian to student monitoring report.

Deans. Subject entry can be handled in this module and also with the registrar module. Student academic inputs are manage here. Reports in this module includes class roster report and subject schedules.

Accounting. This module manages fees both for student and employees. Permits as well as receipts are printed in this module. Reports includes student term fees and student balances.

Guardian Portal. This module handles guardian inquiries. From student payments, grades, appointments, call slips, student attendance and schedule.

Librarian. This module handles borrower's library transactions. Management regarding book inventory is also feature here. Reports include book listing, active borrowers, and data analytic report regarding mostly borrowed books.

Student Portal. This module features management of student inquiries. Grades and schedule can be viewed by students. Downloadable forms are also available for students.

Academic Affairs. This handles grade management. It handles settings of grading systems. It also handles the management of evaluation system both for students and instructors.

Security Office. This module handles the entry management for employees, students and visitors. It has a generation of reports for daily and specified number of days.

Clinic. This module features management of student and employee health concerns. It also covers the management of inventory of medicines in the school. Records of students with disabilities and medical history were managed here.

Human Resource Office. This module manages daily time record of employees. It also handles the management of employee records.

Student Body Organization. This module handles management of student school officers. It covers the 
information dissemination to officers by email and text messaging system.

Student Affairs Office. This module manages the attendance monitoring and verification of students. It also manages the election system of student school officers.

Maintenance Office. This module features management of equipment and materials in the school. It covers the inventory and check-up schedule as well as purchasing new items. Schedule management system for custodians is also presented in this module.

\section{SMS Screenshots}

Fig. 6 below shows the different screenshots of the SMS. User accounts are categorized based on their functionalities. These different modules are interconnected with their functionalities making flow of information faster.

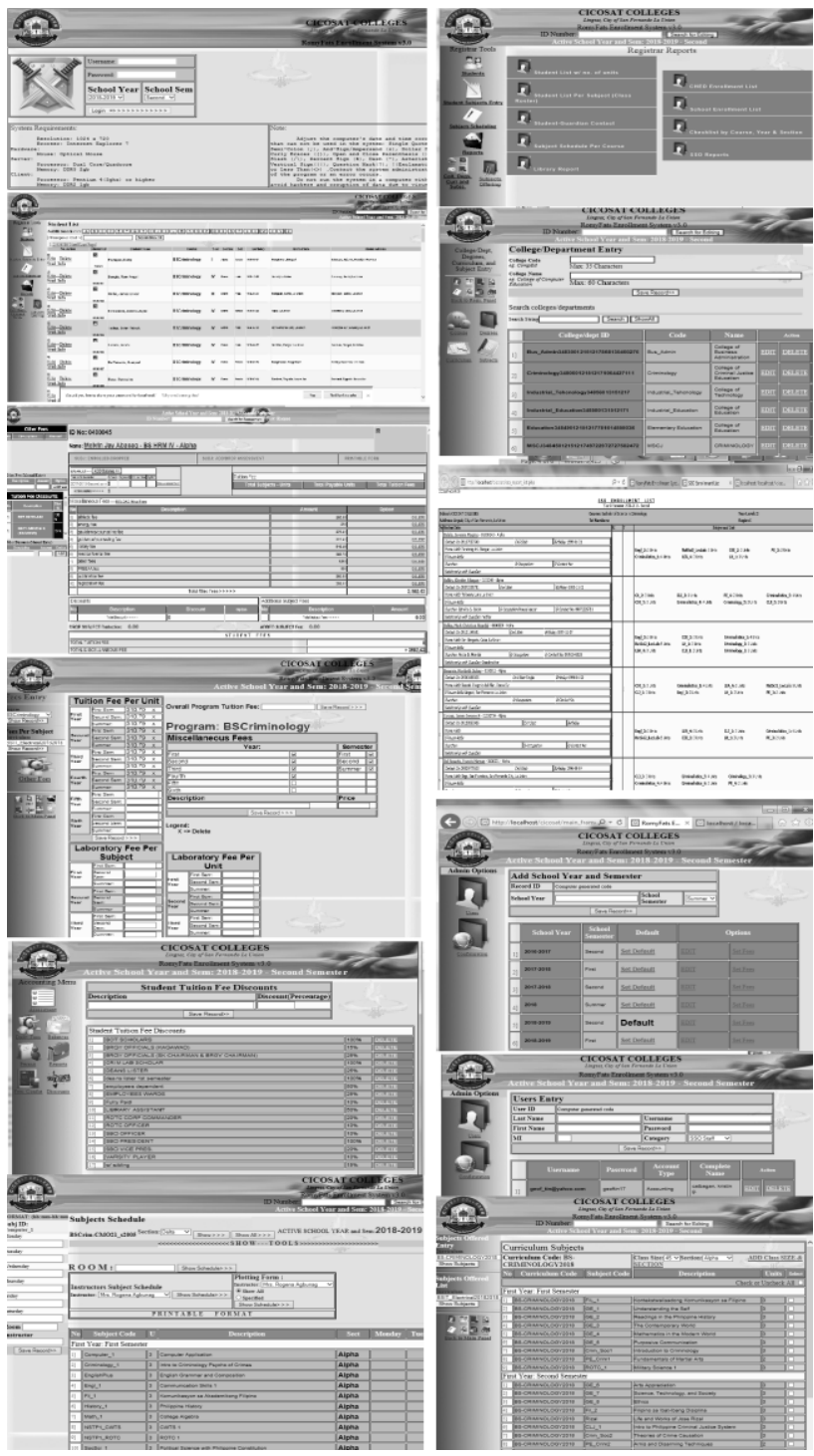

Fig. 6. Screenshots of the SMS

\section{Level of Acceptability}

The SUS questionnaire is given to twenty four (24) respondents. Breakdown are the following: one (1) administrator, one (1) manager, two (2) registrar, two (2) teachers, three (3) librarians, five (5) students and five(5) parents. Fig. 7 shows the chart of the different respondents and Fig. 8 shows the percentage on every questions. The computed average is $87 \%$. The usability score ranged under "acceptable" and has achieved a grade scale of "A" with an adjective equivalent rating "Best Imaginable".

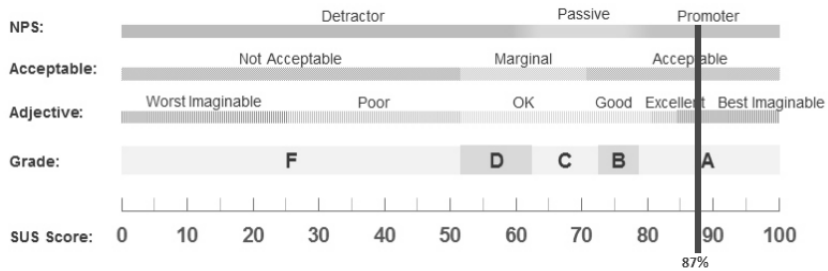

Fig. 7. SUS score equivalent.

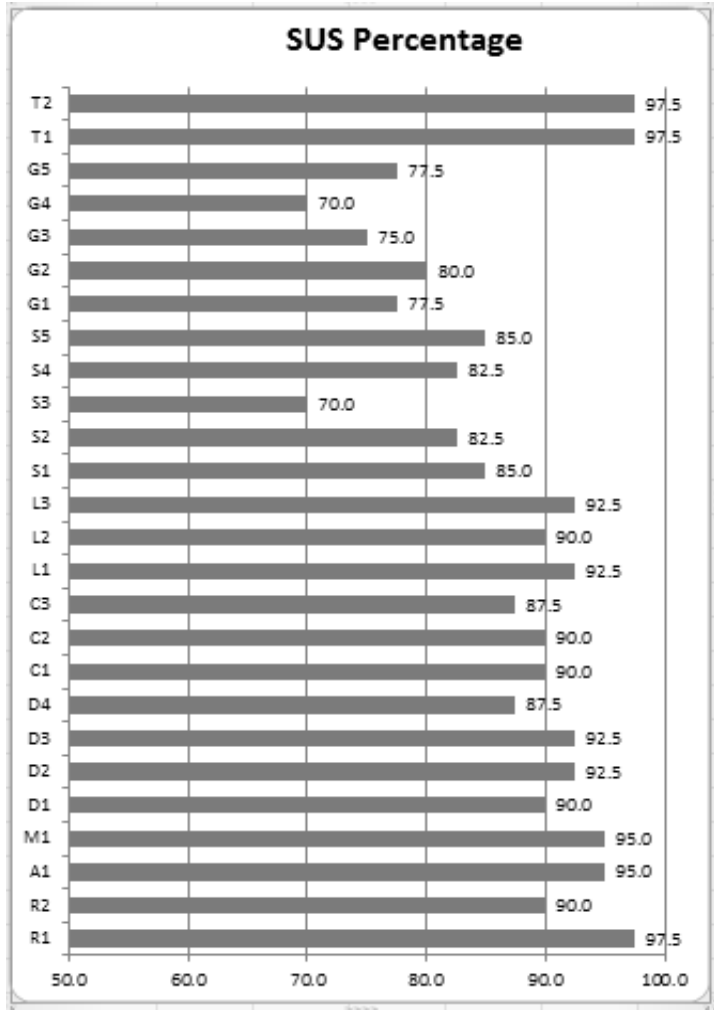

Fig. 8. Respondents SUS SCore.

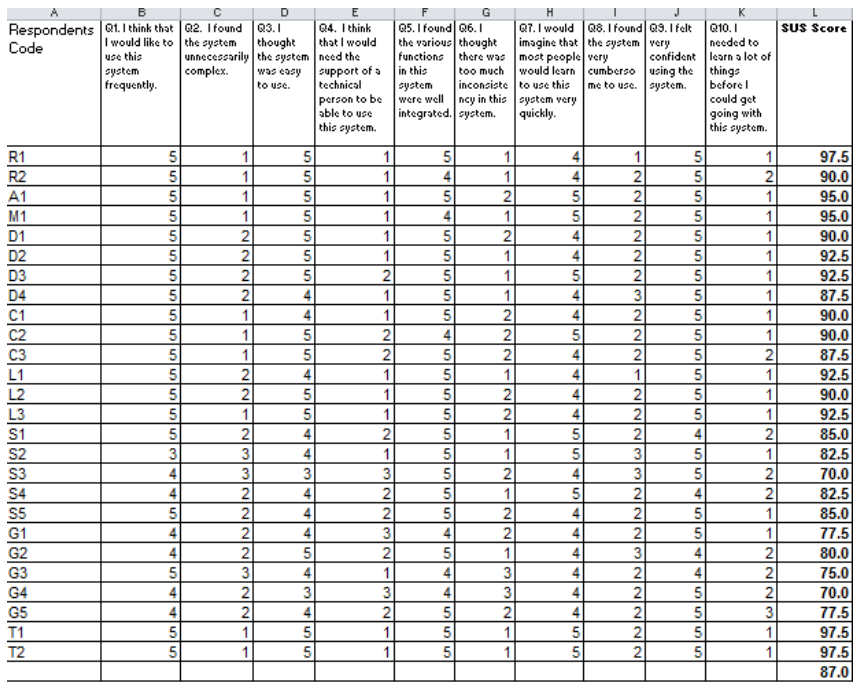

Fig. 9. SUS Questionnaire 5 point scale.

After one month testing, the system is immediately implemented. After six months, SUS questionnaire is given to the respondent to identify their level of acceptability. Based on the result, the respondents are satisfied with the performance of the system. According to the school staff, 
their performance and services provided to the students were improved. Students were also satisfied with the system and their queries were now immediately answered.

Fig. 9 shows the SUS questionnaire with the 5 point scale answer of the respondents. Some of the respondents, in the part of students and guardians, were not that familiar in using computers that gives lower ratings to the system but majority of respondents gives high rating. $\mathrm{R}$ represents Registrar personnel, A for administrator, $\mathrm{M}$ for Manager, D for deans, $\mathrm{C}$ for cashier, L for librarian, $\mathrm{S}$ for students, $\mathrm{G}$ for guardians and $\mathrm{T}$ for teachers.

\section{CONCLUSION}

Integration of SMS using a centralized database and with the use of technologies truly enhances quality of service provided by school in every way. User's level of acceptability proves that the system improves services of the school. User feedbacks are also gathered and help in the improvement of the system. The different existing systems, frameworks and studies became the key component in building the system more efficient. This is not only beneficial to school managers but more importantly to the students and guardians who are the main concern of school management system.

\section{CONFLICT OF INTEREST}

The authors declare no conflict of interest.

\section{AUTHOR CONTRIBUTIONS}

Romeo Balcita conceived and designed the analysis, collected the data, contributed data or analysis tools, performed the analysis, build the system, and wrote the paper. Dr. Therma Palaoag gives insights in making the research.

\section{REFERENCES}

[1] O. Benjamin and O. Kingsley, "Automated school management system - Recipe for viable educational system in developing countries," International Journal of Engineering Trends and Technology, vol. 25, no. 3, 2015,

[2] F. N. Ugwoke and C Samuel, "A Computerized educational administrative information system for post-primary school management board (PPSMB) enugu state," Journal of Software Engineering and Simulation, vol. 2, issue 9, pp. 18-28, 2015.

[3] K. Beycioglu, "Current issues in educational management and leadership," Journal of Management Development, vol. 3, December 2011.

[4] A. A. Owojori and T. O. Asaolu, "Critical Evaluation of personnel management problems in the nigerian school system," Int J Edu Sci. vol. 2, no. 1, pp. 1-11, 2010.

[5] R. E. Anderson and S. Dexter, "School technology leadership: An empirical investigation of prevalence and effect," Educational Administration Quarterly, vol. 41, no. 1, pp. 49-82, 2005.

[6] K. Cowan, K. Vaillancourt, E. Rossen, and K. Pollitt, A Framework for Safe and Successful Schools, Bethesda, MD: National Association of School Psychologists, 2013.

[7] A. Yuen, N. Law, and K. Wong, "ICT implementation and school leadership: Case studies of ICT integration in teaching and learning," Journal of Educational Administration, vol. 41, no. 2, pp. 158-170, 2013.

[8] O. Ogochukwu and C. Ezenwegbu, "Page application of management information system in Chukwuemeka Odumegwu," IOSR Journal of Mobile Computing \& Application, vol. 6, issue 1, 2019.
[9] P. C. Lai, "The literature review of technology adoption models and theories for the novelty technology," JISTEM - Journal of Information Systems and Technology Management, vol. 14, no. 1, pp. 21-38, 2017

[10] F. Ugwoke, "A computerized educational administrative information system for post-primary school management board (PPSMB) Enugu state," Journal of Software Engineering and Simulation, vol. 2, no. 9 , pp. 18-28, 2015

[11] P. Kalay and D. Chen, "Effects of integrating a computerized information system on decision making processes in school management," in Proc. SITE 2004--Society for Information Technology \& Teacher Education International Conference, 2004.

[12] N. Serbedzija, "E-school: A web-based school management system," in Proc. the IASTED International Conference on Computers and Advanced Technology in Education, 2003.

[13] M. Markus, "Alfred P. Sloan School of management. Power, politics, and MIS implementation," Communications of the ACM, vol. 26, no. 6 , pp. 430-444, 1983

[14] V. Banabakova, M. Stoilova, and I. Dacheva, "The management of changes in the system of school education," Knowledge International Journal, vol. 28, no. 3, pp. 743-752, 2018.

[15] Y. Guan, W. Shi, and D. Wu, "The design and development of a schoo file management system for standardized," in Proc. 2012 International Conference on Computer Science and Electronics Engineering, 2012.

[16] Y. Usman, "Educational resources: An integral component for effective school administration," Research on Humanities and Social Sciences, vol. 6, no. 13, 2016.

[17] S. Chen, B. Mulgrew, and P. M. Grant, "A clustering technique for digital communications channel equalization using radial basis function networks," IEEE Trans. on Neural Networks, vol. 4, pp. 570-578, July 1993.

[18] R. Dy, M. J. Laridab, and B. Tanguilig, "e-DoX:DEPED student grade records management system with implementation of advanced encryption standard and PKI infrastructure," International Journal of Sciences: Basic and Applied Research, vol. 11, no. 1, pp. 112-158, 2013.

[19] K. Bipath, "Challenges faced by the school management team (SMT) regarding school safety in South Africa," International Journal of Sciences and Research, vol. 73, no. 3, Mar. 2017.

[20] C. Cheng, School Effectiveness and School-Based Management, Routledge, 2013

Copyright $\odot 2020$ by the authors. This is an open access article distributed under the Creative Commons Attribution License which permits unrestricted use, distribution, and reproduction in any medium, provided the original work is properly cited (CC BY 4.0).

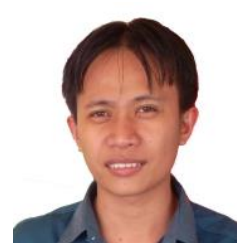

Romeo E. Balcita was born in Bokod, Benguet, Philippines on July 14,1982 . He finished the primary school at Amallapay Elementary School at Amallapay, Tubao, La Union, Philippines; secondary school at Tubao National High School at Tubao, La Union, Phils. He graduated with a bachelor of science in computer science at Colegio De Dagupan at Dagupan City, Phils.; master of information technology (2009) at the University of the Cordilleras at Baguio City, Phils. Currently he is working as the dean of Computer Dept. at Northern Philippines College for Maritime, Science and Technology, Lingsat, San Fernando City, La Union, Philippines. He is the co-author of two papers entitled: Employee-Client Service Management Evaluation Based on Facial Recognition and, School Intrusion Notification and Alarm System Using Face Recognition, both presented at (WCSE 2018) Bangkok, 28-30 June, 2018.

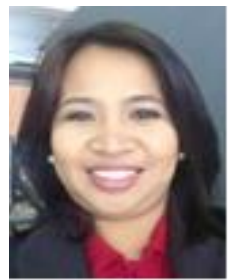

Thelma Domingo Palaoag is the college research coordinator and department head of computer science in College of Information Technology and Computer Science, University of the Cordilleras, Baguio City, Philippines. 